\title{
Elevated neutrophil-lymphocyte ratio in patients with euthyroid chronic autoimmune thyreotidis
}

\author{
${ }^{1}$ Keskin H, ${ }^{2}$ Kaya Y, ${ }^{3}$ Cadirci K, ${ }^{4}$ Kucur C, ${ }^{5}$ Ziypak E, ${ }^{6}$ Simsek E, ${ }^{3}$ Gozcu H, ${ }^{7}$ Arikan S, ${ }^{8}$ Carlioglu A \\ ${ }^{1} 1$ Istanbul Medeniyet University Goztepe Training and Research Hospital, Department of Internal Medicine, \\ Istanbul, Turkey; \\ ${ }^{2}$ Ordu University, Department of Internal Medicine, Ordu, Turkey; \\ ${ }^{3}$ Erzurum Regional Training and Research Hospital, Department of Internal Medicine, Erzurum, Turkey; \\ ${ }^{4}$ Dumlupinar University Evliya Celebi Education and Research Hospital, Department of Ear, Nose, and Throat, \\ Kutahya, Turkey; \\ ${ }^{5}$ Erzurum Regional Training and Research Hospital, Department of Anesthesia and Resuscitation, Erzurum, Turkey; \\ ${ }^{6}$ Erzurum Regional Training and Research Hospital, Department of Ear, Nose, and Throat, Erzurum, Turkey; \\ ${ }^{7}$ Kirikkale University, Department of Endocrinology, Kirikkale, Turkey; \\ ${ }^{8}$ Erzurum Regional Training and Research Hospital, Department of Endocrinology, Erzurum, Turkey \\ E-mail: havva.drkeskin@gmail.com
}

Objective. The neutrophil-lymphocyte ratio (NLR), determined from peripheral blood, is accepted as an available and practical indicator of the systemic inflammation. In this study, we aimed to determine whether the NLR was higher in euthyroid chronic autoimmune thyreotidis (CAT) patients compared to a healthy control group.

Methods. A total of 112 patients were enrolled in this study, including 59 patients with euthyroid CAT on any form of therapy and 53 healthy controls. The CAT patients were similar in age to the healthy control group (mean $33.9 \pm 12.8$ years versus $30.2 \pm 12.4$ years, $\mathrm{p}=0.10$ ). Measurements were available for the white blood cells (WBC), neutrophils, lymphocytes, platelets, C-reactive protein (CRP), thyroid peroxidase immune antibody (anti-TPO), and anti-thyroglobulin immune antibody (anti-TG). The NLR and platelet-lymphocyte ratio (PLR) were calculated. Differences between the CAT and control groups were tested using the student's t-test and the correlations were determined using Pearson's correlation coefficients.

Results. There were no differences between the CAT and control groups for WBCs $(7.9 \pm 0.3$ and $7.4 \pm 0.2$, respectively; $\mathrm{p}=0.1$ ) or neutrophils $(5.5 \pm 0.3$ and $5.4 \pm 1.1 ; \mathrm{p}=0.9)$, but lymphocytes were higher in the CAT group ( $3.1 \pm 0.5$ vs. $2.04 \pm 0.1 ; \mathrm{p}=0.05)$ as was the NLR $(4.0 \pm 0.7$ vs. $2.0 \pm 0.1$; $\mathrm{p}=0.01)$. The NLR was positively correlated with CRP $(\mathrm{r}=0.6, \mathrm{p}<0.001)$, anti-TPO $(\mathrm{r}=0.3, \mathrm{p}<0.001)$, anti-TG $(\mathrm{r}=0.3, \mathrm{p}=0.006)$, WBCs $(\mathrm{r}=0.4, \mathrm{p}<0.001)$, and the PLR $(\mathrm{r}=0.73, \mathrm{p}<0.001)$. The PLR was also higher in the CAT than the control group $(\mathrm{p}=0.02)$.

Conclusions. In this study, we found that NLR values were higher in euthyroid CAT patients than in a healthy control group and that NLR correlated with autoantibodies used to diagnose the disease.

Key words: neutrophil-lymphocyte ratio, euthyroid chronic autoimmune thyreotidis, inflammation

Corresponding author: Havva Keskin, Istanbul Medeniyet University, Training and Research Hospital, Department of Internal Medicine, 34772, Istanbul, Turkey; tel.:+90-452-2252342; fax: +90-452-2250190; havva.drkeskin@gmail.com. 
Chronic autoimmune thyreotidis (CAT) is one of the most common human autoimmune diseases. Thyroid dysfunction occurs in varying degrees and with elevated serum anti-thyroid antibodies levels in CAT patients. It is characterized by diffuse lymphocytic infiltration of the thyroid gland. Despite studies on autoimmune inflammation, the pathogenesis of CAT still remains unclear (Rao et al. 2010; Poplawska-Kita et al. 2015).

Parameters of the hemogram, including immune system elements (neutrophils, lymphocytes, and platelets), are used for the assessment of diseases, and immune system elements play a role in the control of inflammation (Yao et al. 2013; Choi et al. 2014).

Recently, the neutrophil-lymphocyte ratio (NLR) has been shown to be a marker of systemic inflammation (Uslu et al. 2015). The NLR has been widely used to determine the severity of inflammation in cardiovascular disease, malignancies, diabetes mellitus, hypertension, and autoinflammatory diseases (Bhat et al. 2013; Celikbilek et al. 2013). It is also used as a marker of disease activity where it predicts disease progression and mortality (Kaya et al. 2014; Sahin et al. 2013; Rifaioglu et al. 2014; Cho et al. 2015).

In this study, we aimed to determine if the NLR was higher in CAT patients compared to a healthy control group.

\section{Materials and Methods}

Subjects. Fifty-nine patients with euthyroid CAT (9 male, 50 female) did not receiving any replacement therapy were enrolled in the study. They were outpatients at Regional Training and Research Hospital,

Table 1

Comparison of sociodemographic characteristics by case-control status

\begin{tabular}{lccc}
\hline Parameter & $\begin{array}{c}\text { Euthyroid } \\
\text { Hashimoto's } \\
(\mathbf{N = 5 9 )}\end{array}$ & $\begin{array}{c}\text { Controls } \\
(\mathbf{N = 5 3 )}\end{array}$ & $\mathbf{p}$ \\
\hline Age & $33.9 \pm 12.9$ & $30.2 \pm 12.4$ & 0.13 \\
$\begin{array}{l}\text { Males }(\%) \\
\text { Females }(\%)\end{array}$ & $9(15 \%)$ & $27(51 \%)$ & \\
\hline Cigarette $(\%)$ & $50(85 \%)$ & $26(49 \%)$ & $0.000^{*}$ \\
\hline Height $(\mathrm{cm})$ & $163.5 \pm 5.9$ & $165.4 \pm 8.9$ & 0.20 \\
\hline Weight $(\mathrm{kg})$ & $64.5 \pm 11.9$ & $60.5 \pm 11.0$ & 0.10 \\
\hline BMI $\left(\mathrm{kg} / \mathrm{m}^{2}\right)$ & $23.6 \pm 3.3$ & $22.3 \pm 3.7$ & 0.06 \\
\hline $\begin{array}{l}\text { Waist } \\
\text { circumference }(\mathrm{cm})\end{array}$ & $83.5 \pm 12.9$ & $80.8 \pm 10.4$ & 0.36 \\
\hline
\end{tabular}

${ }^{\star}$ Chi-Square Test; BMI - body mass index
Department of Internal Medicine and Endocrinology, Erzurum, Turkey. Fifty-three control subjects (27 male, 26 female) were selected from the healthy relatives of the patients from the same clinics. Pregnant patients or those who had hematologic disease, cancer, severe renal or liver disease, ongoing infection or chronic inflammatory disease, or autoimmune disease were excluded from the study. Height, weight, waist circumference, and venous blood samples of patient and control groups were measured. All complete blood count analyses were performed with an automatic hematologic analyzer. The study was approved by the institutional ethics committee of the Erzurum Regional Training and Research Hospital.

Biochemical and hormone analysis. Fasting blood samples were collected in gel tubes that did not include anticoagulants to measure blood glucose, cholesterol, C-reactive protein (CRP), thyroid stimulating hormone (TSH), free T3 (FT3), free T4 (FT4), thyroid peroxidase immune body (anti-TPO), anti-thyroglobulin immune body (anti-TG), and liver and renal function. An additional blood sample was collected in an EDTA tube and used to measure the hemogram. All the blood samples were collected after $12 \mathrm{~h}$ overnight fasting and centrifuged at $1800 \times \mathrm{g}$ for $15 \mathrm{~min}$ before analyzing.

Biochemical parameters were measured colorimetrically using Abbott original reagents in an Abbott Architect c8000 autoanalyzer.

Total white blood cell (WBC), neutrophil, lymphocyte, and platelet counts were determined with a Sysmex XE-2100 Hematology Analyzer (Sysmex Corp., Kobe, Japan). The NLR was defined as the absolute neutrophil count divided by the absolute lymphocyte count. The platelet-lymphocyte ratio (PLR) was defined as the absolute neutrophil count divided by the absolute platelet count.

Statistical Analysis. Statistical analyses were performed using the Statistical Package for the Social Sciences (SPSS), Version 20. Descriptive statistics were used to summarize all measurements. All continuous data are shown as mean \pm standard deviation. The euthyroid CAT group and the control group were compared using the chi-square test and student's t-test. Pearson's (for continuous data) and Spearman's (for ordinal data) tests were used for correlation analyses. Multiple linear regression analysis was used to detect independent variables of euthyroid CAT. The level of statistical significance was established at $\mathrm{p}<0.05$.

\section{Results}

Mean age of patients group was $33.9 \pm 12.9$ years and mean age of control group was $30.2 \pm 12.4$ years. CAT 
Table 2

Comparison of complete blood count and biochemical parameters by case-control status

\begin{tabular}{|c|c|c|c|}
\hline Parameter & $\begin{array}{l}\text { Euthyroid Hashimoto's } \\
(\mathrm{N}=59)\end{array}$ & $\begin{array}{c}\text { Controls } \\
(\mathrm{N}=53)\end{array}$ & $\mathbf{p}$ \\
\hline Hemoglobin (g/dl) & $14.1 \pm 1.5$ & $15.7 \pm 1.4$ & 0.02 \\
\hline White Blood Cell $(\times 10 . e 3 / \mathrm{ul})$ & $7.9 \pm 2.2$ & $7.4 \pm 1.4$ & 0.18 \\
\hline Neutrophil (×10.e3/ul) & $5.6 \pm 2.5$ & $5.5 \pm 8$ & 0.94 \\
\hline Lymphocytes $(\times 10 . e 3 /$ ul $)$ & $2.1 \pm 0,8$ & $3.1 \pm 3.8$ & 0.05 \\
\hline Neutrophil-Lymphocyte Ratio & $4.01 \pm 5.0$ & $2.0 \pm 1.1$ & 0.01 \\
\hline Platelet (×10.e3/ul) & $263.8 \pm 671$ & $2561 \pm 54.7$ & 0.53 \\
\hline Platelet-Lymphocyte Ratio & $145.5 \pm 95.2$ & $110.1 \pm 44.7$ & 0.02 \\
\hline Mean platelet volume $(\mathrm{fl})$ & $8.8 \pm 1.0$ & $7.9 \pm 0.8$ & 0.00 \\
\hline C-reactive protein $(\mathrm{mg} / \mathrm{dl})$ & $4.1 \pm 8.4$ & $1.9 \pm 1.4$ & 0.25 \\
\hline Mean Corpuscular Volume (fl) & $86.1 \pm 5.6$ & $86.8 \pm 3.6$ & 0.47 \\
\hline Mean Corpuscular Hemoglobin Concentration (fl) & $34.1 \pm 1.2$ & $33.7 \pm 4.2$ & 0.54 \\
\hline Total TSH (mIU/l) & $1.8 \pm 0.8$ & $1.8 \pm 1.1$ & 0.69 \\
\hline FreeT3 (pg/ml) & $3.1 \pm 0.7$ & $3.3 \pm 0.8$ & 0.30 \\
\hline FreeT4 (ng/dl) & $1.2 \pm 0.4$ & $1.5 \pm 0.8$ & 0.08 \\
\hline Thyroid Peroxidase Antibody (IU/ml) & $428.3 \pm 668.3$ & $14.8 \pm 9.7$ & 0.003 \\
\hline Anti-Thyroglobulin (IU/ml) & $320.5 \pm 796.0$ & $21.3 \pm 26.2$ & 0.007 \\
\hline Fasting blood glucose (mg/dl) & $90.3 \pm 10.0$ & $86.7 \pm 7.6$ & 0.09 \\
\hline Total cholesterol (mg/dl) & $198.2 \pm 42.7$ & $176.3 \pm 46.0$ & 0.05 \\
\hline LDL-cholesterol & $110.2 \pm 38.8$ & $123.1 \pm 33.0$ & 0.16 \\
\hline HDL-cholesterol (mg/dl) & $57.0 \pm 19.8$ & $56.5 \pm 15.3$ & 0.91 \\
\hline Triglycerides (mg/dl) & $133.8 \pm 91.8$ & $90.2 \pm 41.1$ & 0.01 \\
\hline Urea (mg/dl) & $28.0 \pm 7.3$ & $30.5 \pm 8.6$ & 0.18 \\
\hline Creatinine (mg/dl) & $0.7 \pm 0.2$ & $0.8 \pm 0.1$ & 0.15 \\
\hline Alanine Amino Transferase (mg/dl) & $19.3 \pm 10.3$ & $19.2 \pm 13.7$ & 0.97 \\
\hline Aspartat Amino Transferase (mg/dl) & $21.2 \pm 6.1$ & $20.9 \pm 6.1$ & 0.81 \\
\hline Gamma-Glutamyl Transferase (mg/dl) & $19.1 \pm 13.1$ & $15.7 \pm 8.9$ & 0.17 \\
\hline Alkaline Phosphatase (mg/dl) & $185.7 \pm 57.5$ & $234.2 \pm 211.2$ & 0.16 \\
\hline
\end{tabular}

patients were more frequently female than subjects in the control group $(\mathrm{p}<0.001)$. Socio-demographic characteristics of study participants are presented in Table 1.

The NLR in the CAT cases was significantly higher than in the healthy control group. Similarly, the PLR was significantly higher in the case than the control group. In contrast, lymphocyte counts were lower in cases than controls. No associations with CAT disease were observed for WBC count, neutrophil count, anti-TPO levels, or anti-TG levels (Table 2). A positive correlation was seen between NLR and CRP, anti-TPO, anti-TG, WBC count, and PLR (Table 3).

Multivariate regression analysis showed that the NLR was a risk factor for euthyroid CAT disease independent of body mass index (BMI), age, and gender (Table 4). 
Table 3

Correlation of the neutrophil-lymphocyte ratio with other laboratory parameters

\begin{tabular}{lcc}
\hline NLR & $\mathbf{r}$ & $\mathbf{p}$ \\
\hline Total TSH & -0.175 & 0.117 \\
FreeT3 & -0.127 & 0.309 \\
FreeT4 & -0.065 & 0.58 \\
Thyroid PeroxidaseAntibody & 0.379 & $\mathbf{0 . 0 0 1}$ \\
\hline Anti-Thyroglobulin & 0.324 & $\mathbf{0 . 0 0 6}$ \\
C-reactive protein & 0.6 & $\mathbf{0 . 0 0 0}$ \\
\hline White Blood Cell & 0.4 & $\mathbf{0 . 0 0 0}$ \\
PLR & 0.73 & $\mathbf{0 . 0 0 0}$ \\
\hline
\end{tabular}

NLR - Neutrophil-Lymphocytes Rate; PLR - Platelet Lymphocytes Rate

Table 4

Multiple linear regression to determine the Euthtyroid Hashimoto independent predictors

\begin{tabular}{lcc}
\hline Parameter & $\boldsymbol{\beta}$ & $\mathbf{p}$ \\
\hline NLR & 0.259 & 0.010 \\
Age (year) & -0.071 & 0.579 \\
BMI & 0.129 & 0.305 \\
Gender & -0.467 & 0.000 \\
\hline
\end{tabular}

NLR: Neutrophil-Lymphocytes Rate; BMI: body mass index

\section{Discussion}

In this study, we demonstrated that the NLR and the PLR are higher in the patients with euthyroid CAT disease without any replacement therapy than controls while lymphocyte counts were lower. Positive correlations were seen between the NLR and CRP, anti-TPO, anti-TG, WBC count, the PLR. The PLR was found higher in the patient group.

Etiology and systemic involvement of CAT are still unknown (Poplawska-Kita et al. 2015). The results of studies emphasize that neutrophils, platelets, and lymphocytes are important in inflammation (Feng et al. 2014; Kemal et al. 2014). Neutrophils lead to the production of cytokines (Wang and Arase 2014), and cytokines play a significant role in the pathogenesis of inflammatory diseases. Cytokines also activate neutrophils and platelets (Jaillon et al. 2013;
Feng et al. 2014; Deng et al. 2015). Platelets also have an active role in the inflammation and regulatory effects on the immune system (Boilard et al. 2010; Choi et al. 2014). It is a huge advantage that all of these parameters of inflammation (levels of neutrophils, platelets, lymphocytes, NLR, and PLR) can routinely and cheaply be measured in the peripheral blood.

Some studies have reported that NLR and PLR were used as inflammatory marker in autoimmune diseases. According to the results of these studies, they were found that higher NLR and PLR in patients with rheumatoid arthritis than healthy subjects' control group (Uslu et al. 2015). Additionally, higher NLRs have been reported in patients with familial Mediterranean fever, ulcerative colitis, and psoriasis diseases (Guthrie et al. 2013; Ahsen et al. 2013; Sen et al. 2014). In the current study, we found higher NLR and PLR in patients with euthtyroid CAT compared to controls.

Neutrophils abnormalities in their activation may lead to an autoimmunity and tissue damage (Kaplan et al. 2013). Moodley et al. (2011) have reported as a result of study that lymphocytes have early apoptotic markers and this may be associated with autoimmunity and lymphopenia. Experimental studies have shown that platelets have role in the regulation of innate and adaptive immunity (Semple and Freedman 2010). Sprague et al. (2008) have reported that platelet microparticles may activate adaptive immune cells, trigger antibody synthesis, and alter lymphocyte activities. Platelet microparticles may stimulate an immune response (Italiano et al. 2010). In our study, although the PLR and the NLR were higher in patients than controls, no correlation between the PLR and autoimmune antibodies was found.

CRP is one of the major components of inflammatory reactions. Inflammation, infection, and tissue injury may increase the CRP (Ansar and Ghosh 2013). CRP has been shown to increase autoimmune diseases such as pyoderma gangrenosum and ulcerative colitis (Rowe et al. 1986; Turner et al. 2011).

In this study, we found that the NLR is a risk factor of euthyroid CAT independent from BMI, age, and gender (Table 4). Present symptoms show that the NLR increased values in the euthyroid CAT are statistically significant in comparison with healthy control group. It correlated with autoantibody level, which is used for the diagnosis of disease. These results indicate that systemic inflammatory process is important in the CAT etiology. 


\section{References}

Ahsen A, Ulu MS, Yuksel S, Demir K, Uysal M, Erdogan M, Acarturk G. As a new inflammatory marker for familial Mediterranean fever: neutrophil-to-lymphocyte ratio. Inflammation 36, 1357-1362, 2013.

Ansar W, Ghosh S. C-reactive protein and the biology of disease. Immunol Res 56, 131-142, 2013.

Bhat T, Teli S, Rijal J, Bhat H, Raza M, Khoueiry G, Meghani M, Akhtar M, Costantino T. Neutrophil to lymphocyte ratio and cardiovascular diseases: a review. Expert Rev Cardiovasc Ther 11, 55-59, 2013.

Boilard E, Nigrovic PA, Larabee K, Watts GF, Coblyn JS, Weinblatt ME, Massarotti EM, Remold-O'Donnell E, Farndale RW, Ware J, Lee DM. Platelets amplify inflammation in arthritis via collagen-dependent microparticle production. Science 327, 580-583, 2010.

Celikbilek M, Dogan S, Ozbakır O, Zararsız G, Kucuk H, Gursoy S, Yurci A, Guven K, Yucesoy M. Neutrophil lymphocyte ratio as a predictor of disease severity in ulcerative colitis. J Clin Lab Anal 27, 72-76, 2013.

Cho JS, Park MH, Ryu YJ, Yoon YH. The neutrophil to lymphocyte ratio can discriminate anaplastic thyroid cancer against poorly or well differentiated cancer. Ann Surg Treat Res 88, 187-192, 2015.

Choi JL, Li S, Han JY. Platelet function tests: a review of progresses in clinical application. Biomed Res Int 456569, 2014.

Deng Q, He B, Liu X, Yue J, Ying H, Pan Y, Sun H, Chen J, Wang F, Gao T, Zhang L, Wang S. Prognostic value of preoperative inflammatory response biomarkers in gastric cancer patients and the construction of a predictive model. J Transl Med 13, 66, 2015.

Feng JF, Huang Y, Chen QX. Preoperative platelet lymphocyte ratio (PLR) is superior to neutrophil lymphocyte ratio (NLR) as a predictive factor in patients with esophageal squamous cell carcinoma. World J Surg Oncol 12, $58,2014$.

Guthrie GJ, Charles KA, Roxburgh CS, Horgan PG, McMillan DC, Clarke SJ. The systemic inflammation-based neutrophil-lymphocyte ratio: experience in patients with cancer. Crit Rev Oncol Hematol 88, 218-230, 2013.

Italiano JE Jr, Mairuhu AT, Flaumenhaft R. Clinical relevance of microparticles from platelets and megakaryocytes. Curr Opin Hematol 17, 578-84, 2010.

Jaillon S, Galdiero MR, Del Prete D, Cassatella MA, Garlanda C, Mantovani A. Neutrophils in innate and adaptive immunity. Semin Immunopathol 35, 377-94, 2013.

Kaplan MJ. Role of neutrophils in systemic autoimmune diseases. Arthritis Res Ther 15, 219-228, 2013.

Kaya A, Kurt M, Tanboga HI, Isik T, Gunaydin ZY, Kaya Y, Topcu S, Sevimli S. Relation of neutrophil to lymphocyte ratio with the presence and severity of stable coronary artery disease. Clin Appl Thromb Hemost 20, 473-477, 2014.

Kemal Y, Yucel I, Ekiz K, Demirag G, Yilmaz B, Teker F, Ozdemir M. Elevated serum neutrophil to lymphocyte and platelet to lymphocyte ratios could be useful in lung cancer diagnosis. Asian Pac J Cancer Prev 15, 2651-2654, 2014.

Moodley D, Mody GM, Chuturgoon AA. Initiation but no execution - modulation of peripheral blood lymphocyte apoptosis in rheumatoid arthritis - a potential role for heat shock protein 70. J Inflamm (Lond) 8, 30, 2011.

Poplawska-Kita A, Kosciuszko-Zdrodowska M, Siewko K, Telejko B, Hryniewicka J, Milewski R, Abdelrazek SS, Szelachowska M, Gorska M. High serum Ig G4 concentrations in patients with Hashimoto's Thyroiditis. Int J Endocrinol 2015, 706843, 2015.

Rao NL, Shetty S, Upadhyaya K, Prasad RM, Lobo EC, Kedilaya HP, Prasad G. Salivary C-Reactive Protein in Hashimoto's Thyroiditis and Subacute Thyroiditis. Int J Inflam 2010, 514659, 2010.

Rifaioglu EN, Sen BB, Ekiz O, Dogramaci AC. Neutrophil to lymphocyte ratio in Behcet's disease as a marker of disease activity. Acta Dermatovenerol APA 23, 65-67, 2014.

Rowe IF, Deans AC. Serum C-reactive protein measurement in pyoderma gangrenosum. Dermatologica 173, 216219, 1986.

Sahin S, Sarikaya S, Alcelik A, Erdem A, Tasliyurt T, Akyol L, Altunkas F, Aktas G, Karaman K. Neutrophils to lymphocyte ratio is a useful predictor of atrial fibrillation in patients with diabetes mellitus. Acta Medica Mediterranea 29, 847-851, 2013.

Sen BB, Rifaioglu EN, Ekiz O, Inan MU, Sen T, Sen N. Neutrophil to lymphocyte ratio as a measure of systemic inflammation in psoriasis. Cutan Ocul Toxicol 33, 223-227, 2014.

Semple JW, Freedman J. Platelets and innate immunity. Cell Mol Life Sci 67, 499-511, 2010.

Sprague DL, Elzey BD, Crist SA, Waldschmidt TJ, Jensen RJ, Ratliff TL. Platelet-mediated modulation of adaptive immunity: unique delivery of CD154 signal by platelet-derived membrane vesicles. Blood 111, 5028-5036, 2008. 
Turner D, Mack DR, Hyams J, LeLeiko N, Otley A, Markowitz J, Kasirer Y, Muise A, Seow CH, Silverberg MS, Crandall W, Griffiths AM. C-reactive protein (CRP), erythrocyte sedimentation rate (ESR) or both? A systematic evaluation in pediatric ulcerative colitis. J Crohns Colitis 5, 423-429, 2011.

Uslu AU, Kucuk A, Sahin A, Ugan Y, Yilmaz R, Gungor T, Bagdaci S, Kucuksen S. Two new inflammatory markers associated with Disease Activity Score-28 in patients with rheumatoid arthritis: neutrophil-lymphocyte ratio and platelet-lymphocyte ratio. Int J Rheum Dis 18, 731-735, 2015.

Wang J, Arase H. Regulation of immune responses by neutrophils. Ann N Y Acad Sci 1319, 66-81, 2014.

Yao Y, Simard AR, Shi FD, Hao J. IL-10-producing lymphocytes in inflammatory disease. Int Rev Immunol 32, 324-336, 2013. 